\section{ANALISIS PENDAPATAN DAN BIAYA KAITANNYA DENGAN PENYAJIAN LABA KOTOR PT. JATROPHA OIL INDONESIA}

\author{
Siti ita Rosita dan Ribut Yudi S \\ Program Studi Akuntansi, Sekolah Tinggi Ilmu Ekonomi Kesatuan \\ Bogor, Indonesia \\ Email : lemlit@stiekesatuan.ac.id
}

Revenues and

expenses

recognition, gross

profit.

024

Submitted: JANUARI 2016

Accepted:

FEBRUARI 2016

activities and one that is not. Revenues resulted from normal activities usually obtained from goods or services selling relating to company's main activities. Expenses are deducting factors of revenues to obtain profits and/or loss. Expenses arised form company's activities are consisted of production costs, business costs and other costs. Gross profits is more actually operative in character when compared to operating profit, Even though gross profit is often perceived to normally depicting company's normal activities, not all costs reflected in operating costs are directly related to the creation of revenues. The research is to analyse revenues and expenses recognition in a manufacturing company. Analysis is conducted to investigate whether or not the recognition of expenses and revenues run by the company is accountable to compile gross profit and then be used to evaluate the production department performance. The result shows that the company has properly recognised the revenues obtained, but not in the expenses part. This is due to the improper method used.

Key words: Revenues and expenses recognition, gross profit.

\title{
PENDAHULUAN
}

Secara umum pencapaian laba optimum merupakan tujuan setiap pendirian perusahaan. Karena itu untuk mencapai tujuan tersebut pada kondisi sekarang ini diperlukan kecermatan pelaksana atau pengelola perusahaan untuk melakukan sinergi yang kuat antar masing-masing bagian dalam organisasi perusahaan. Sinergi integral dari seluruh bagian-bagian dalam perusahaan akan dapat mendukung kelancaran operasional perusahaan yang pada akhirnya diharpkan akan dapat mencapai tujuan perusahaan.

Diantara berbagai kebijakan perusahaan, salah satu fungsi penting adalah bagaimana pengakuan pendapatan dan beban pada perusahaan. Fungsi ini dikatakan cukup penting karena sumber laba perusahaan berasal dari pendapatan dan beban sehingga perlu diketahui pengakuan atas pendapatan dan beban bagi perusahaan agar tidak terjadi kesalahan pencatatan. Untuk perusahaan kecil dan memiliki jumlah penjualan terbatas, pengakuan atas pendapatan dan beban bukanlah masalah rumit. Tetapi bagi perusahaan besar dalam skala penjualan besar, pengakuan pendapatan dan beban telah menjadi masalah rumit dan kompleks.

Secara umum laba merupakan selisih antara keseluruhan pendapatan dan beban suatu perusahaan dalam suatu periode tertentu. Dengan kata lain, pendapatan dan beban merupakan unsur penting dalam menyajikan informasi dalam laporan keuangan. Oleh sebab itu, diperlukan adanya pengakuan yang tepat terhadap unsur pendapatan dan beban.

Pengakuan pendapatan dan beban dilakukan dengan mencatat dan mencantumkan sesuai dengan nilai yang seharusnya. Bila pendapatan maupun beban yang diakui tidak sama dengan yang seharusnya (terlalu besar atau terlalu kecil),

\section{JIAKES \\ Jurnal Ilmiah Akuntansi Kesatuan Vol. 4 No. 1,2016 pg. $024-034$
STIE Kesatuan ISSN $2337-7852$}


Revenues and expenses recognition, gross profit maka informasi yang disajikan dalam laporan laba rugi menjadi tidak tepat dan tidak akurat, yang akhirnya mempengaruhi kewajaran laporan keuangan itu sendiri.

Laporan laba rugi merupakan salah satu jenis laporan keuangan. Laporan ini sendiri merupakan laporan yang menunjukan kegiatan perusahaan selama periode tertentu dalam menghasilkan laba. Hal tersebut bisa dilihat dari seberapa banyak pendapatan yang dihasilkan dan seberapa besar biaya yang dikeluarkan.

Di dalam laporan laba rugi ada 3 (tiga) jenis laba, yaitu: laba kotor, laba bersih sebelum pajak, dan laba bersih setelah dipotong pajak. Laba kotor sebenarnya lebih operatif sifatnya dibandingkan laba operasi. Walaupun laba operasi didefinisikan sebagai laba yang mampu menggambarkan operasi normal perusahaan, namun tidak seluruh biaya yang tergambar di dalam rekening biaya-biaya operasi merupakan biaya yang berhubungan langsung dengan penciptaan pendapatan.

\section{MAKSUD DAN TUJUAN}

1. Untuk mengetahui pengukuran dan pengakuan pendapatan pada PT. Jatropha Oil Indonesia.

2. Unuk mengetahui pengukuran dan pengakuan biaya pada PT. Jatropha Oil Indonesia

3. Untuk mengetahui penentuan dan penyajian laba kotor pada PT. Jatropha Oil Indonesia

\section{TINJAUAN PUSTAKA}

Ada beberapa teori yang mendukung penelitian yaitu Menurut Suwardjono (2005, 367) menyatakan bahwa Pendapatan baru diakui setelah suatu produk selesai diproduksi dan penjualan benar-benar telah terjadi yang ditandai dengan penyerahan barang. Dengan kata lain, pendapatan belum dapat dinyatakan akan diakui sebelum terjadinya penjualan yang nyata. Hal ini didasarkan pada gagasan bahwa pengakuan suatu jumlah rupiah dalam akuntansi harus didasarkan pada konsep dasar keterukuran dan reliabilitas jumlah rupiah harus cukup pasti dan ditentukan secara objektif oleh pihak independen.

Menurut Theodorus M. Tuanakootta (2001, 155) pengukuran pendapatan adalah sebagai berikut : Cara terbaik untuk mengukur pendapatan (revenue) adalah dengan menggunakan nilai tukar (exchange value) dari barang atau jasa. Nilai tukar ini merupakan cash equivalent (ekuivalen kas) atau Present Value (Nilai Sekarang) dari tagihan yang diharapkan akan diterima dari Transaksi pendapatan (revenue) ini. Dalam kebanyakan hal, ini adalah harga yang sudah disepakati dengan langganan.

Pelaporan biaya yang ada dalam laporan keuangan dibagi dua metode yaitu :

1. Metode kas basis

Menurut Kieso Weygandt Warfield (2011, 117) "cash basis of accounting records revenues when cash is received and expenses when cash is paid."

2. Metode akrual basis

Menurut Keiso Weygandt Warfield (2011, 117) “accrual basis recognizes revenue when earned and expenses in the period incurred, without regard to the time of the receipt or payment of cash." 
Biaya dapat diukur dengan menjumlahkan rupiah yang dipergunakan untuk penilaian akitiva dalam hal ini diukur dengan satuan moneter, oleh karena itu pengukuran biaya dapat didasarkan pada:

1. Harga perolehan historis

2. Harga berlaku (current price)

3. Opportunity cost (biaya oportunitas atau ekuivalen kas pada saat berjalan)

Menurut Jerrry J. Weygandt, Donald E. Kieso dan Paul D. Kimmel (2005, 277) yang diterjemahkan oleh Ali Akbar Yulianto, Wasilah dan Rangga Handika menyatakan "Terdapat dua bentuk laporan laba rugi yang paling sering digunakan oleh perusahaan dagang."

\section{METODE PENELITIAN}

Metode penelitian yang digunakan adalah metode deskriptif kualitatif yaitu penulis akan menguraikan atau menjelaskan pengukuran dan pengakuan pendapatan dan biaya dalam kaitannya dengan penentuan laba kotor pada objek penelitian yang dipilih. Dalam meninjau pengukuran dan pengakuan pendapatan dan biaya tersebut, penulis akan membandingkannya dengan PSAK terkait.

\section{HASIL DAN PEMBAHASAN}

PT. Jatropha Oil Indonesia menyajikan laba kotor dengan maksud untuk mengukur tingkat efektifitas bagian produksi. Tetapi dengan adanya perbedaan antara pengakuan pendapatan dan pengakuan biaya PT. Jatropha Oil Indonesia mengalami kesulitan untuk mengukur tingkat efektifitas bagian produksi.

Di dalam mengakui pendapatan PT. Jatropha Oil Indonesia menggunakan metode dasar akrual. Hal ini menandakan PT. Jatropha Oil Indonesia mengakui pendapatan dengan keadaan sebenarnya pada saat terjadi penjualan akan terjadi piutang kepada pihak pembeli.

Berbeda dengan pendapatan, biaya di PT. Jatropha Oil Indonesia diakui dengan menggunakan metode dasar kas. Hal ini menandakan PT. Jatropha Oil Indonesia mengakui biaya bukan pada keadaan sebenarnya. Pada saat terjadi pembelian PT. Jatropha Oil Indonesia tidak terjadi hutang pada pihak supplier dan perusahaan juga belum mencatat bertambahnya bahan baku atas pembelian. Pencatatan bahan baku baru akan dicatat pada saat PT. Jatropha Oil Indonesia membayar kepada pihak supplier. Keadaan seperti ini mempengaruhi laporan harga pokok produksi PT. Jatropha Oil Indonesia dan tentunya akan berpengaruh pada laba kotor PT. Jatropha Oil Indonesia.

Harga pokok produksi merupakan jumlah dari biaya-biaya yang berkaitan langsung untuk menghasilkan barang yang siap untuk dijual, harga pokok poduksi juga menentukan harga jual dari suatu barang. Harga pokok produksi PT. Jatropha Oil Indonesia dari bulan Oktober sampai dengan Desember 2012 adalah senilai: Rp. 94,351,911 untuk bulan Oktober, Rp. 56,324,003 untuk bulan November dan Rp. 216,336,000 untuk bulan Desember. Untuk lebih jelasnya penulis akan melampirkan laporan Harga Pokok Produksi PT. Jatropha Oil Indonesia selama bulan Oktober sampai dengan Desember 2012.
Revenues and expenses recognition, gross profit

\section{6}


Revenues and expenses recognition, gross profit

$\underline{027}$

Tabel 1

Laporan Harga Pokok Penjualan Bulan Oktober 2012

\begin{tabular}{|l|l|l|}
\hline Persediaan awal & & Rp. $19,072,539$ \\
\hline Overhead pabrik & & \\
\hline \multicolumn{1}{|c|}{ Biaya langsung } & & \\
\hline Gaji tenaga kerja langsung harian & Rp. 19,150,000 & \\
\hline Gaji tenaga kerja langsung borongan & Rp . 7,283,100 & \\
\hline Uang makan tenaga kerja langsung & Rp. 4,650,000 & \\
\hline Listrik & Rp. 35,949,092 & \\
\hline Pupuk dan bahan kimia & Rp. 27,700,000 & \\
\hline THR & - & \\
\hline Lembur & - & \\
\hline Total overhead pabrik & & Rp. 94,732,192 \\
\hline Persediaan tersedia & & Rp. 113,804,731 \\
\hline Persediaan akhir & & Rp. 19,452,820) \\
\hline Harga pokok penjualan & & Rp. 94,351,911 \\
\hline
\end{tabular}

Tabel 2

Laporan Harga Pokok Penjualan Bulan November 2012

\begin{tabular}{|l|l|l|}
\hline Persediaan awal & & Rp. 19,452,820 \\
\hline Overhead pabrik & & \\
\hline Biaya langsung & & \\
\hline Gaji tenaga kerja langsung harian & Rp. 19,150,000 & \\
\hline Gaji tenaga kerja langsung borongan & Rp. 23,013,825 & \\
\hline Uang makan tenaga kerja langsung & Rp. 4,500,000 & \\
\hline Listrik & Rp. 48,990,019 & \\
\hline Pupuk dan bahan kimia & - & \\
\hline THR & - & \\
\hline Lembur & - & \\
\hline Total overhead pabrik & & Rp. 95,653,844 \\
\hline Persediaan tersedia & & Rp. 115,106,664 \\
\hline Persediaan akhir & & (Rp. 56,732,161) \\
\hline Harga pokok penjualan & & Rp. 58,374,503 \\
\hline
\end{tabular}

Tabel 3

Laporan Harga Pokok Penjualan Bulan Desember 2012

\begin{tabular}{|l|l|l|}
\hline Persediaan awal & & Rp. 56,732,161 \\
\hline Overhead pabrik & & \\
\hline Biaya langsung & & \\
\hline Gaji tenaga kerja langsung harian & Rp. 19,150,000 & \\
\hline Gaji tenaga kerja langsung borongan & - & \\
\hline Uang makan tenaga kerja langsung & Rp. 4,500,000 & \\
\hline Listrik & Rp. 79,654,633 & \\
\hline Pupuk dan bahan kimia & Rp. 59,292,500 & \\
\hline THR & - & \\
\hline Lembur & - & \\
\hline Total overhead pabrik & & Rp. 162,597,133 \\
\hline Persediaan tersedia & & Rp. 219,329,294 \\
\hline Persediaan akhir & & (Rp. 3,863,151) \\
\hline Harga pokok penjualan & & Rp. 215,466,143 \\
\hline
\end{tabular}

Dari data yang dilampirkan oleh penulis diatas menunjukan bahwa metode pengakuan biaya sangat penting bagi laporan harga pokok produksi yang nantinya 
akan mempengaruhi penyajian laba kotor PT. Jatropha Oil Indonesia yang akan digunakan untuk mengukur efektifitas bagian produksi.

Laporan harga pokok produksi yang disajikan oleh PT. Jatropha Oil Indonesia juga masih sangat lemah karena tidak menampilkan semua pos yang berlaku secara umum. PT. Jatropha Oil Indonesia tidak menampilkan pos barang dalam proses. Barang dalam proses cukup penting karena mempengarugi harga pokok produksi.

Dapat diambil contoh pada bulan November menunjukan harga pokok produksi yang paling kecil yaitu senilai Rp. 58,374,503 akan tetapi di bulan November terjadi pembelian pupuk dan bahan kimia ini disebabkan karena PT. Jatropha Oil Indonesia mengakui adanya pembelian pada saat uang dikeluarkan (metode dasar kas). Hal ini membuat pihak manajemen kesulitan untuk mengambil langkah ke depan untuk perusahaan karena ketidak akuratan data yang diperoleh.

Dengan keadaan seperti ini juga penyajian laba kotor juga tidak sesuai dengan keadaan yang sebenernya. Untuk lebih jelasnya penulis akan melampirkan laporan laba kotor dari PT. Jatropha Oil Indonesia untuk bulan Oktober sampai dengan Desember 2012.

Tabel 4

Laporan Laba Kotor Bulan Oktober 2012

\begin{tabular}{|l|l|l|}
\hline Penjualan & & Rp. 582,950,400 \\
\hline Retur penjualan & - & \\
\hline Penjualan bersih & & Rp. 582,950,400 \\
\hline Harga pokok prenjualan & & (Rp. 94,351,911) \\
\hline Laba kotor & & Rp. 488,598,489 \\
\hline
\end{tabular}

Tabel 5

Laporan Laba Kotor Bulan November 2012

\begin{tabular}{|l|l|l|}
\hline Penjualan & & Rp. 791,961,600 \\
\hline Retur penjualan & - & \\
\hline Penjualan bersih & & Rp. 791,961,600 \\
\hline Harga pokok penjualan & & (Rp. 58,374,503) \\
\hline Laba kotor & & Rp. 733,587,097 \\
\hline
\end{tabular}

Tabel 6

Laporan Laba Kotor Bulan Desember 2012

\begin{tabular}{|l|l|l|}
\hline Penjualan & & Rp. 750,042,900 \\
\hline Retur penjualan & - & \\
\hline Penjualan bersih & & Rp. 750,042,900 \\
\hline Harga pokok penjualan & & (Rp. 215,466,143) \\
\hline Laba kotor & & Rp. 534,576,757 \\
\hline
\end{tabular}

Dari data yang dilampirkan penulis diatas dapat dilihat kenaikan penjualan paling besar yaitu dari bulan Oktober 2012 sampai bulan Novmber 2012 yaitu sekitar 26,39\% berbeda dengan dari bulan November 2012 sampai bulan Desember 2012 terjadi penurunan yaitu sekitar (5,59\%). Hal ini disebabkan pada bulan Oktober 2012 sampai dengan November 2012 hasil panen biji jarak pagar yang merupakan bahan baku utama bagi PT. Jatropha Oil Indonesia untuk menghasilkan bio solar cukup melimpah dikerenakan cuaca yang cukup bagus untuk tanaman jarak pagar yaitu cuaca yang lembab.

Berbeda dengan prnjualan kenaikan yang paling besar untuk harga pokok produksi PT. Jatropha Oil Indonesia terjadi pada bulan November 2012 sampai dengan Desember 2012 yaitu sekitar 73,96\% dan terjadi penuran dari bula Oktober 2012 sampai denan November 2012 yaitu sekitar (67,52\%). Hal ini disebabkan karena PT. Jatropha Oil Indonesia menggunakan metode dasar kas atas pengakuan
Revenues and expenses recognition, gross profit

$\underline{028}$ 
Revenues and expenses recognition, gross profit

$\underline{029}$ biaya yang dikeluarkan oleh PT. Jatropha Oil Indonesia. Keadaan seperti ini berpengaruh pada harga pokok produksi.

Sedangkan dilihat dari laba kotor perushaan terjadi kenaikan yaitu dari bulan Oktober 2012 sampai dengan November 2012 yaitu sekitar 33,58\%. Dalam keadaan sebenernya PT. Jatropha Oil Indonesia pada bulan November 2012 membeli pupuk dan bahan kimia untuk meningkatkan hasil panen karena cuaca yang sedang mendukung, strategi yang diterapkan PT. Jatropha Oil Indonesia berhasil dengan meningkatkan penjualan sebesar Rp. 209,011,200 tetapi pembelian itu belum dicatat oleh perusahaan.

Sedangkan biaya yang dikeluarkan PT. Jatropha Oil Indonesia menggunakan metode dasar kas sehingga pada bulan Desember 2012 terjadi kenaikan yang cukup besar untuk biaya yang dikeluarkan karena pada bulan Desember pembelian bulan November baru dibayarkan. Hal ini menyebabkan pada bulan Desember 2012 PT. Jatropha Oil Indonesia mengalami penurunan laba kotor sekitar $(37,84 \%)$. Hal ini sungguh tidak menggambarkan keadaan produksi sebenarnya karena menejer produksi tidak bisa menilai efektifitas kinerja bawahannya. Dan menejer produksi pun sulit mengambil keputusan untuk menetukan langkah produksi kedepannya.

Untuk lebih jelasnya tentang aktivitas PT. Jatropha Oil Indonesia penulis akan melampirkan laporan laba rugi perusahaan selama bulan Oktober sampai dengan Desember 2012.

Tabel 6

Laporan Laba Rugi Bulan Oktober 2012

\begin{tabular}{|c|c|c|}
\hline Penjualan & & Rp. 582,950,400 \\
\hline Retur penjualan & - & \\
\hline Penjualan bersih & & Rp. 582,950,400 \\
\hline Harga pokok penjualan & & (Rp. 94,351,911) \\
\hline Laba kotor & & Rp. $488,598,489$ \\
\hline \multicolumn{3}{|l|}{ Beban aadministrasi dan umum } \\
\hline Bahan bakar & Rp. 5,131,340 & \\
\hline Parkir dan tol & Rp. $1,634,000$ & \\
\hline Spareparts & Rp. 2,031,316 & \\
\hline Telepon dan fax & Rp. $1,749,385$ & \\
\hline Sumbangan & Rp. 300,000 & \\
\hline Depresiasi kendaraan & Rp. $4,710,000$ & \\
\hline $\begin{array}{l}\text { Depresiasi infrastruktur } \\
\text { nursery }\end{array}$ & Rp. $\quad 879,690$ & \\
\hline Depresiasi system pengairan & Rp. $1,937,267$ & \\
\hline Depresiasi peralatan kantor & Rp. $\quad 524,300$ & \\
\hline Asuransi & Rp. $\quad 525,500$ & \\
\hline Perizinan & Rp. $4,675,000$ & \\
\hline Medical & Rp. $4,798,400$ & \\
\hline Transportasi & Rp. $1,826,760$ & \\
\hline Biaya rumah tangga & Rp. $1,133,402$ & \\
\hline Research and development & Rp. $1,437,000$ & \\
\hline Gaji & Rp. $63,505,700$ & \\
\hline Asuransi tenaga kerja & Rp. $12,353,700$ & \\
\hline Perlengkapan kamtor & Rp. $\quad 923,620$ & \\
\hline Pajak & Rp. $4,585,000$ & \\
\hline Tenaga professional & Rp. $5,000,000$ & \\
\hline Perjalanan dinas & Rp. 16,304,744 & \\
\hline Demo project & - & \\
\hline Total beban operasi dan umum & & Rp. $135,966,124$ \\
\hline Laba operasi & & Rp. 352,632,365 \\
\hline
\end{tabular}




\begin{tabular}{|l|l|l|}
\hline Pendapatan (beban) lain-lain & & \\
\hline Pendapatan bunga & Rp. 974,679 & \\
\hline Pendapatan lain-lain & - & \\
\hline Beban bunga & (Rp. 2,013,516) & \\
\hline Beban lain-lain & - & (Rp. 1,038,837) \\
\hline $\begin{array}{l}\text { Total pendapatan (beban) lain- } \\
\text { lain }\end{array}$ & & Rp. 351,593,528 \\
\hline Laba (rugi) bersih & & \\
\hline
\end{tabular}

Revenues and expenses recognition, gross profit

Tabel 7

Laporan Laba Rugi Bulan November 2012

\begin{tabular}{|c|c|c|}
\hline Penjualan & & Rp. 791,961,600 \\
\hline Retur penjualan & - & \\
\hline Penjualan bersih & & Rp. 791,961,600 \\
\hline Harga pokok penjualan & & $\begin{array}{l}\text { (Rp. } \\
58,374,503)\end{array}$ \\
\hline Laba kotor & & Rp. 733,587,097 \\
\hline \multicolumn{3}{|l|}{ Beban administrasi dan umum } \\
\hline Bahan bakar & Rp. 193,794 & \\
\hline Parkir dan tol & 5,500 & \\
\hline Spareparts & - & \\
\hline Telepon dan fax & $\begin{array}{l}\text { Rp. } \\
392,000\end{array}$ & \\
\hline Sumbangan & Rp. $2,450,000$ & \\
\hline Depresiasi kendaraan & Rp. $4,710,000$ & \\
\hline Depresiasi infrastruktur nursery & Rp. $\quad 879,690$ & \\
\hline Depresiasi system pengairan & Rp. $1,937,267$ & \\
\hline Depresiasi peralatan kantor & Rp. $\quad 524,300$ & \\
\hline Asuransi & Rp. $\quad 525,500$ & \\
\hline Perizinan & - & \\
\hline Medical & Rp. $1,156,000$ & \\
\hline Transportasi & Rp. $1,610,000$ & \\
\hline Biaya rumah tangga & Rp. $2,235,058$ & \\
\hline Research and development & - & \\
\hline Gaji & Rp. 63,505,700 & \\
\hline Asuransi tenaga kerja & - & \\
\hline Perlengkapan kamtor & Rp. $\quad 566,000$ & \\
\hline Pajak & Rp. $5,000,000$ & \\
\hline Tenaga professional & Rp. $5,000,000$ & \\
\hline Perjalanan dinas & Rp. 22,140,911 & \\
\hline Demo project & Rp. 29,897,995 & \\
\hline $\begin{array}{l}\text { Total biaya adminidtrasi dan } \\
\text { umum }\end{array}$ & & Rp. $142,729,715$ \\
\hline Laba operasi & & Rp. 590,857,382 \\
\hline \multicolumn{3}{|l|}{ Pendapatan (beban) lain-lain } \\
\hline Pendapatan bunga & Rp. $\quad 595,700$ & \\
\hline Pendapatan lain-lain & - & \\
\hline Beban bunga & (Rp. 1,686,503) & \\
\hline Beban lain-lain & - & \\
\hline Total pendapatan (beban) lain- & & (Rp. $1,090,803)$ \\
\hline
\end{tabular}


Revenues and

expenses

recognition,

gross profit

\section{1}

\begin{tabular}{|l|l|l|}
\hline lain & & \\
\hline Laba (rugi) bersih & & Rp. 589,766,579 \\
\hline
\end{tabular}

Tabel 8

Laporan Laba Rugi Bulan Desember 2012

\begin{tabular}{|c|c|c|}
\hline Penjualan & & Rp. 750,042,900 \\
\hline Retur penjualan & - & \\
\hline Penjualan bersih & & Rp. $750,042,900$ \\
\hline Harga pokok penjualan & & $\begin{array}{l}(\mathrm{Rp} \\
215,466,143)\end{array}$ \\
\hline Laba kotor & & Rp. 534,576,757 \\
\hline \multicolumn{3}{|l|}{ Beban administrasi dan umum } \\
\hline Bahan bakar & Rp. $4,833,441$ & \\
\hline Parkir dan tol & Rp. $1,064,000$ & \\
\hline Spareparts & Rp. $3,954,400$ & \\
\hline Telepon dan fax & Rp. $1,130,749$ & \\
\hline Sumbangan & Rp. $5.056,000$ & \\
\hline Depresiasi kendaraan & Rp. $1,937,267$ & \\
\hline Depresiasi infrastruktur nursery & $\begin{array}{ll}\text { Rp. } & 769,505 \\
\end{array}$ & \\
\hline Depresiasi system pengairan & Rp. $4,833,441$ & \\
\hline Depresiasi peralatan kantor & Rp. $1,064,000$ & \\
\hline Asuransi & Rp. $\quad 525,500$ & \\
\hline Perizinan & Rp. $10,022,300$ & \\
\hline Medical & Rp. $1,636,500$ & \\
\hline Transportasi & Rp. $2,099,894$ & \\
\hline Biaya rumah tangga & $\begin{array}{ll}\text { Rp. } & 255,777 \\
\end{array}$ & \\
\hline Research and development & Rp. $1,749,000$ & \\
\hline Gaji & Rp. $63,505,700$ & \\
\hline Asuransi tenaga kerja & Rp. $8,235,800$ & \\
\hline Perlengkapan kamtor & Rp. $1,005,450$ & \\
\hline Pajak & Rp. $4,324,842$ & \\
\hline Tenaga professional & Rp. $48,990,000$ & \\
\hline Perjalanan dinas & Rp. $8,421,784$ & \\
\hline Demo project & Rp. $9,860,817$ & \\
\hline $\begin{array}{l}\text { Total biaya adminidtrasi dan } \\
\text { umum }\end{array}$ & & Rp. $184,968,416$ \\
\hline Laba operasi & & Rp. 349,608,341 \\
\hline \multicolumn{3}{|l|}{ Pendapatan (beban) lain-lain } \\
\hline Pendapatan bunga & Rp. $\quad 683,890$ & \\
\hline Pendapatan lain-lain & - & \\
\hline Beban bunga & (Rp. 1,519,225) & \\
\hline Beban lain-lain & - & \\
\hline $\begin{array}{l}\text { Total pendapatan (beban) lain- } \\
\text { lain }\end{array}$ & & (Rp. 835,335) \\
\hline Laba (rugi) bersih & & Rp. $348,773,006$ \\
\hline
\end{tabular}

Dari data diatas perusahaan mengakui biaya-biaya yang dikeluarkan dengan metode dasar kas, sebaiknya perusahaan mengakui biaya-biaya tersebut dengan metode dasar akrual agar ada kesamaan untuk membandingkan antara pendapatan yang diterima dan biaya yang dikeluarkan oleh perusahaan. Sebagai contoh dalam pembelian barang sebaiknya diakui pada saat barang itu dibeli bukan pada saat kas 
dikeluarkan karena barang yang dibeli itu sudah terpakai. Contoh Jurnalnya: Pada tanggal 15 November 2012 perusahaan melakukan pembelian pupuk dan bahan kimia senilai Rp. 59,292,500 jangka waktu pembayaran 40 hari. Maka jurnalnya:

\begin{tabular}{|l|l|l|}
\hline Pembelian & $59,592,500$ & \\
\hline Hutang Dagang & & $59,592,500$ \\
\hline
\end{tabular}

Selain itu perusahaan juga belum menyajikan laba kotor dengan baik karena ada pos-pos yang tidak ditampilkan perusahaan dalam menyusun harga pokok produksi sehingga harga pokok penjualan terlalu kecil dan laba menjadi besar, pospos yang tidak ditampilkan seperti persedian barang dalam proses, persediaan bahan baku dan penyusutan mesin produksi. Sebaiknya perusahaan menampilkan pos-pos tersebut agar laba kotor yang disajikan perusahaan dapat menyediakan informasi yang lebih akurat tentang kegiatan perusahaan.

Untuk lebih jelasnya berikut penulis lampirkan laporan harga pokok produksi dan harga pokok penjualan dengan menggunakan metode dasar akrual untuk biaya-biaya yang dikeluarkan dan menampilkan pos-pos dalam harga pokok produksi yang belum ditampilkan perusahaan.

Tabel 9

Laporan Harga Pokok Produksi November 2012

\begin{tabular}{|l|l|l|}
\hline Persediaan Barang Dalam Proses & & Rp. 10,000,000 \\
\hline Persediaan Awal Bahan Baku & Rp. 5,000,000 & \\
\hline Pembelian & Rp. 59,592,500 & \\
\hline Tersedia Dipakai & RP. 64,592,500 & \\
\hline Persediaan Akhir & (Rp. 9,000,000) & \\
\hline Bahan Baku Dipakai & & Rp. 55,592,500 \\
\hline Tenaga Kerja Langsung & & Rp. 46,663,825 \\
\hline Overhead & & \\
\hline Listrik & & Rp. 48,990,019 \\
\hline Penyusutan Mesin & & Rp. 2,816,597 \\
\hline Total Biaya Barang dalam Proses & & Rp. 164,063,301 \\
\hline Persediaan barang dalam proses & & (Rp. 18,000,000) \\
\hline Harga Pokok Produksi & & Rp.146,063,301 \\
\hline
\end{tabular}

Tabel 10

Harga Pokok Penjualan Bulan November 2012

\begin{tabular}{|l|l|l|}
\hline Persediaan Barang Jadi Awal & & Rp. 19,452,820 \\
\hline Harga Pokok Produksi & Rp.146,063,301 & \\
\hline Persediaan Akhir & $($ Rp.56,732,161) & \\
\hline & & Rp. 89,331,140 \\
\hline Harga Pokok Penjualan & & Rp. 108,783,960 \\
\hline
\end{tabular}

Berdasarkan data di atas penulis mencoba menyusun harga pokok produksi dan harga pokok penjualan dengan menggunakan metode dasar akrual. Dengan demikian dapat dilihat perusahaan terlalu kecil menyajikan harga pokok penjualan sebesar Rp. 50,409,457 sehingga laba yang disajikan perusahaan pun menjadi semakin besar.

\section{SIMPULAN}

1. PT. Jatropha Oil Indonesia mengakui pendapatan dengan meggunakan dasar akrual yaitu pengakuan pendapatan saat pendapatan diperoleh walaupun kas belum diterima.
Revenues and expenses recognition, gross profit 
Revenues and expenses recognition, gross profit

\section{3}

2. PT. Jatropha Oil Indonesia mengakui biaya-biaya dengan menggunakan dasar kas yaitu pengakuan biaya ketika biaya tersebut dibayarkan secara kas. Dalam hal ini terkait dengan pembelian bahan baku.

3. Pembebanan biaya produksi pada PT. Jatropha Oil Indonesia masih belum tepat. Hal ini dikarenakan tidak ada pengalokasian biaya listrik untuk bagian kantor, sehingga semua biaya listrik dibebankan ke pabrik. Sedankan biaya penyusutan seluruhnya dibebankan ke bagian kantor tidak ada biaya penyusutan untuk bagian pabrik.

4. PT. Jatropha Oil Indonesia belum menyajikan laba kotor yang tepat, karena pengakuan pendapatan dan biaya menggunakan dasar pengakuan yang berbeda.

\section{DAFTAR PUSTAKA}

Ahmad Riahi dan Belkaoui, 2006, Teori Akuntansi, Salemba Empat, Jakarta Harahap Sofyan Syafri, 2003, Teori Akuntansi, PT. Raja Grafindo Persada, Jakarta Haryono Jusup, 2005, Dasar-Dasar Akuntansi, Edisi Keenam, STIE YKPN, Jogjakarta

Hendriksen, 2001, Teori Akuntansi, Alih Bahasa: Herman Wibowo, PT. Raja Grafindo Persada, Jakarta.

Horngren Charles T., Srikant M. Datardan George Foster, 2008, Cost Accounting Amanegerial Emphasis (Akuntansi Biaya Dengan Penekanan Manajerial), Alih Bahasa: P.A Lestari, Erlangga, Jakarta

Ikatan Akuntansi Indonesia, 2002, Standar Akuntansi Keuangan, Salemba Empat, Jakarta.

Ikatan Akuntansi Indonesia, 2004, Standar Akuntansi Keuangan, Salemba Empat, Jakarta.

Kasihanto, 2008, Analisa Penerapan PSAK no.28 Asuransi Kerugian Terhadap Pengakuan Pendapatan dan Biaya pada Perusahaan Asuransi PT. Asuransi Bumiputeramuda 1967, diseminarkan di STIE Kesatuan Bogor

Kieso Donald E., Jerry J. Weygandt dan Terry D. Warfield, 2002, Akuntansi intermediate, Ahli bahasa: Herman Wibowo dan Ancella A. Hermawan, Erlangga, Jakarta

Kieso Donald E., Jerry J. Weygandt dan Terry D. Warfield, 2007, Akuntansi intermediate Jilid 1,Edisi 12, Ahli bahasa: Emil Salim, Erlangga, Jakarta

Kieso Weygandt Warfield, 2011, Intermediate accounting, volume satu, Hokoben, New Jersey

Mulyadi, 2002, Akuntansi Biaya, Salemba Empat, Jakarta.

Santoso Imam, 2009, Akuntansi Keuangan Menengah 2, PT. Refika Aditama, Bandung

Simangunsong, Ao., E. Paruliah dan J. Endang KS, 2007, Pengantar Akuntansi, Buku 1, Fakultas Ekonomi UI, Depok

Soemaeso, 2005, Akuntansi Suatu Pengantar, PT. Rineka Cipta, Jakarta.

Stice, Earl K., James D. Stice dan K. Fred Skousen, 2004, Akuntansi Keuangan 1, Edisi 15, Salemba Empat, Jakarta

Suhesri, 2009, Analisa Perubahan Laba Kotor Terhadap Efesiensi Perusahaan, diseminarkan di STIE Kesatuan Bogor

Suwardjono, 2005, Teori Akuntansi Perekayasaan Pelaporan Keuangan, Edisi 3, Bpfe, Yogyakarta.

Tuanakootta Theodorus M., 2001, Teori Akuntansi, PT. Raja Grafindo Persada, Jakarta 
Warren Carl S., James M. Reeve dan Philip E. Fees, 2008, Accounting (Pengantar Akuntansi) 1, Edisi 21, Alih bahasa: Aria Farahmita, Amanugrahani danTaufik Hendrawan, Salemba Empat, Jakarta

Weygandt, Jerry J, Donald E. Kieso, Paul D. Kimmel, 2005, Accounting Principle (Pengantar Akuntansi), Buku 1, Edisi 7, Alih Bahasa: Ali Akbar Yulianto dan Rangga Handika, Salemba Empat, Jakarta.
Revenues and expenses recognition, gross profit

034 